\title{
Spatial Distribution and Determinants of Nonautonomy on Decision Regarding Contraceptive Utilization among Married Reproductive-Age Women in Ethiopia: Spatial and Bayesian Multilevel Analysis
}

\author{
Setognal Birara Aychiluhm $\mathbb{D}^{1},{ }^{1}$ Kusse Urmale Mare $\mathbb{D}^{\mathbb{D}},{ }^{2}$ Mequannent Sharew Melaku $\mathbb{D}^{3}{ }^{3}$ \\ and Abay Woday Tadesse $\mathbb{D}^{1,4}$ \\ ${ }^{1}$ Department of Public Health, College of Medicine and Health Sciences, Samara University, Samara, Ethiopia \\ ${ }^{2}$ Department of Nursing, College of Medicine and Health Sciences, Samara University, Samara, Ethiopia \\ ${ }^{3}$ Department of Health Informatics, Institute of Public Health, College of Medicine and Health Sciences, \\ University of Gondar, Gondar, Ethiopia \\ ${ }^{4}$ Dream Science and Technology College, Amhara Regional State, Dessie, Ethiopia
}

Correspondence should be addressed to Setognal Birara Aychiluhm; geez4214@gmail.com

Received 10 May 2021; Revised 7 September 2021; Accepted 22 October 2021; Published 5 November 2021

Academic Editor: Janaka Lenora

Copyright ( 92021 Setognal Birara Aychiluhm et al. This is an open access article distributed under the Creative Commons Attribution License, which permits unrestricted use, distribution, and reproduction in any medium, provided the original work is properly cited.

Background. Studies conducted to date in Ethiopia did not explore the spatial distribution, individual-level, and community-level factors affecting women's nonautonomy on decision to use contraceptives. Hence, this study aimed to assess the spatial distribution of women's nonautonomy on decision regarding contraceptive utilization and its determinants in Ethiopia. Methods. Data were accessed from the Demographic Health Survey program official database website (https://dhsprogram.com). A weighted sample of 3,668 married reproductive-age women currently using contraceptives was included in this analysis. Bayesian multilevel logistic regression models were fitted to identify the determinants of women's nonautonomy on contraceptive utilization. Adjusted odds ratio with 95\% credible interval was used to select variables that have a significant effect on nonautonomy on contraceptive utilization. Results. A high proportion of women with nonautonomy on decision regarding contraceptive utilization was found in northern parts of Southern Nations, Nationalities, and People's Region, Southern parts of Oromia, and Benishangul-Gumuz regions of the country. Overall, 2876 (78.40\% (95\% CI: 77.0\%, 79.7\%)) women were nonautonomous on decision regarding contraceptive utilization. In the final model, age from $35-49$ (AOR $(95 \% \mathrm{CI})=0.63(0.54,0.72))$, living in the richer households $(\mathrm{AOR}(95 \% \mathrm{CI})=0.12(0.03,0.26))$, being married at 18 years or above $(\mathrm{AOR}(95 \% \mathrm{CI})=0.33(0.19,0.57))$, and residing in an rural areas $(\mathrm{AOR}(95 \% \mathrm{CI})=1.34(1.01,1.71))$ and metropolitan regions $(\mathrm{AOR}(95 \% \mathrm{CI})=0.71(0.54,0.91))$ were associated with women's nonautonomy on decision regarding contraceptive utilization. Conclusions. In Ethiopia, the spatial distribution of women's nonautonomy on decision about contraceptive utilization was nonrandom. More than three-fourths of married reproductive-age women in Ethiopia are nonautonomous on decision regarding contraceptive utilization. Region, residence, current age, age at marriage, and wealth index were statistically associated with women's nonautonomy on decision regarding contraceptive utilization.

\section{Background}

Although women's decision-making autonomy on sexual and reproductive health is crucial for better maternal and child health outcomes, restriction of open communication between partners due to gender-based power inequalities limits women's access to sexual and reproductive health services, particularly contraceptives [1]. The findings of different studies have shown the effects of women's autonomy on contraception utilization [2-4], and it is one of 
the influential sociocultural factors determining women's uptake of their preferred contraceptives [5-10]. In the settings where women are less autonomous on decision regarding contraceptive utilization, a low proportion of women use contraceptives [5, 11].

Globally, $45 \%$ of married women were nonautonomous on decision regarding SRH issues, with $64 \%$ in sub-Saharan Africa [12]. In Ethiopia, the existing evidence shows a considerable variation in the women's nonautonomy on decision regarding contraceptive utilization across different geographical areas that ranges from $20 \%$ to $78 \%$ [13-18]. Several studies conducted across the world have identified different community- and individual-level factors affecting women's nonautonomy on decision regarding contraceptive utilization [15-24].

Different strategies, policies, and programs have been strived in the past decades to improve safe motherhood at global, regional, and national levels [25]. In Ethiopia, promoting the use of SRH services and information as part of the reproductive health strategy [26], the incorporation of women's rights to information and rights to be protected from the risk of unwanted pregnancy through the use of contraceptive methods into the country's constitution [27], and implementation of five-year Health Sector Transformation Plan strategies $[26,28]$ were the efforts taken to improve reproductive health. Despite this, nearly $76 \%$ of women are nonautonomous on decision regarding contraceptive utilization in Ethiopia [21].

Studies conducted previously did not explore the spatial distribution of women's nonautonomy on decision regarding contraceptive utilization. Besides, individual- and community-level factors affecting women's nonautonomy on contraceptive utilization are not well investigated.

Identifying spatial distribution and determinants of women's nonautonomy helps to take targeted interventions and has become important to define geographical areas with women's nonautonomy on contraceptive utilization using Geographic Information Systems (GISs) and Spatial Scan Statistical (SaTScan) analyses. Besides, it could also be used as input for policymakers and programmer managers of the study area in the field of public health. Therefore, this study aimed to assess the spatial distribution of women's nonautonomy on decision regarding contraceptive utilization and its determinants in Ethiopia using Bayesian multilevel analysis.

\section{Materials and Methods}

2.1. Data Source, Study Period, Study Design, and Procedures. Data were retrieved from the Demographic and Health Survey (DHS) program official database website (https:// dhsprogram.com), which were collected from January 18 to June 27, 2016. The Ethiopian Demographic and Health Survey (EDHS) is a nationally representative survey conducted every five years in the nine regional states (Afar, Amhara, Benishangul-Gumuz, Gambela, Harari, Oromia, Somali, Southern Nations, Nationalities, and People's Region, and Tigray) and two administrative cities (Addis Ababa and Dire-Dawa) of Ethiopia [29]. A total weighted sample of 3,668 married reproductive-age women currently using contraceptives was included in this study. The detailed sampling procedure exists in the full EDHS 2016 report [29].

\subsection{Study Variables}

2.2.1. Dependent Variable. The outcome variable of this study was "women's autonomy on decision regarding contraceptive utilization." The outcome variable was dichotomized into "nonautonomous $=1$ " and “autonomous $=0$."

2.2.2. Independent Variables. Independent variables were classified into individual-level variables and communitylevel variables. Individual-level variables were the respondent's age, couple's age difference, marital status, type of marriage, women's education level, husband's education level, husband's occupation, respondent's occupation, wealth index, religion, exposure to mass media, age at marriage, and the number of living children. Communitylevel variables were region, residence, community media exposure, community women education level, and community poverty level. The community-level explanatory variables were constructed by aggregating individual-level characteristics at the community (cluster) level, and categorization of the aggregated variables was carried out as high or low based on the distribution of the proportion values calculated for each community.

2.3. Data Management and Statistical Analysis. We used ArcGIS version 10.6 and Spatial Scan Statistics (SaTScanTM version 9.6) software to perform the spatial data analysis. Global Moran's index (Moran's I) was used to measure spatial autocorrelation. Getis-Ord $\mathrm{Gi}^{*}$ statistics were applied for hotspot analysis. Spatial scan statistics were applied to detect significant clusters. The scan statistics were developed using the Bernoulli model by applying by Kulldorff and SaTScan ${ }^{\mathrm{TM}}$ software version 9.6 to determine the presence of purely spatial nonautonomy on contraceptive utilization clusters.

Sample weights to the EDHS data were applied to estimate proportions and frequencies to adjust disproportionate sampling and nonresponse. A full clarification of the weighting procedure was explained in the 2016 EDHS report [29]. The analysis was performed using Stata version 16.0.

2.4. Convergence Assessment for Bayesian Multilevel Modeling. In this study, Markov Chain Monte Carlo (MCMC) simulation with Metropolis-Hastings sampling algorithm was carried out. To assess the convergence algorithm in our study, we used time-series (history) plots, density plots, and autocorrelation plots, and Gelman-Rubin statistics was used to assess whether the sample had reached stationary distribution or not.

2.5. Model Comparison and Selection. We have fitted four models that contain predictors of interest for this study: model I (null model), a model without independent variables 
to test random variability in the intercept and to estimate the intraclass correlation coefficient and proportion change in variance (PCV); model II, a model with only individual-level explanatory variables; model III, a model with only community-level explanatory variables; and model IV (full model), a model with both individual- and community-level predictors.

Deviance information criterion (DIC) value was used for model selection criteria, and the model with a low DIC value was considered as a more likely best-fitted model for this analysis. From the models fitted, model IV (full model), a model with both individual- and community-level predictors, has the smallest DIC value. Hence, model IV (full model) most likely fits the data.

Summary statistics were carried out from the posterior distribution, and adjusted odds ratio (AOR) with 95\% Bayesian credible interval in the Bayesian multivariable multilevel analysis was used to select variables that have a statistically significant effect on women's nonautonomy on decision regarding contraceptive utilization.

2.6. Ethical Consideration. The data were accessed from the DHS website (https://www.measuredhs.com) after being registered and permission was obtained. The retrieved data were used for this registered research only. The data were treated as confidential, and no determination was made to identify any household or individual respondent.

\section{Results}

3.1. Sociodemographic Characteristics of the Study Participants. Out of the total respondents, 2,806 (76.5\%) women resided in rural settings, 1,948 (53.1\%) did not attend formal education, and 1,750 (47.7\%) of the respondents' age ranged from 25-34 years. In this study, 1,988 (54.2\%) of the study participants did not have exposure to mass media (Table 1).

\subsection{Spatial Distribution of Nonautonomy on Contraceptive} Utilization. The spatial distribution of women's nonautonomy on contraceptive utilization in Ethiopia was nonrandom. The global Moran's I value was 0.082 ( $P$ value $<0.001)$. Nonautonomous women on decision regarding contraceptive utilization were higher in Tigray, Amhara, eastern part of Afar, Eastern and Northern Somali, Benishangul-Gumuz, northern parts of SNNPR, Gambela, and Oromia regions. A low proportion of nonautonomous women was observed in Addis Ababa, Dire-Dawa, some parts of Amhara, Afar, Tigray, Gambela, and Oromia regions (Figure 1(a)).

3.3. Hotspot Analysis (Getis-Ord Gi*Statistic). High (hotspot) areas for nonautonomous women on contraceptive utilization were identified in northern parts of SNNPR, Southern parts of Oromia, and Benishangul-Gumuz regions which are represented in red color in Figure 1(b).
TABLE 1: Weighted sociodemographic characteristics of the study participants, Ethiopia, 2016.

\begin{tabular}{|c|c|}
\hline Variables & Frequency (\%) \\
\hline \multicolumn{2}{|l|}{ Residence } \\
\hline Urban & $8629(23.50)$ \\
\hline Rural & $2,806(76.50)$ \\
\hline \multicolumn{2}{|l|}{ Religion } \\
\hline Orthodox & $1,877(51.17)$ \\
\hline Protestant & $968(26.38)$ \\
\hline Muslim & $768(20.94)$ \\
\hline Others $^{+}$ & $55(1.51)$ \\
\hline \multicolumn{2}{|l|}{ Age (years) } \\
\hline 15-24 years & $850(23.18)$ \\
\hline $25-34$ years & $1,750(47.70)$ \\
\hline $3-49$ years & $1,068(29.12)$ \\
\hline \multicolumn{2}{|l|}{ Age at first marriage } \\
\hline$<18$ years & $1,397(38.08)$ \\
\hline$\geq 18$ years & $2,271(61.92)$ \\
\hline \multicolumn{2}{|c|}{ Respondent's educational status } \\
\hline No education & $1,948(53.10)$ \\
\hline Primary & $1,146(31.25)$ \\
\hline Secondary and above & $574(15.65)$ \\
\hline \multicolumn{2}{|c|}{ Husband's educational status } \\
\hline No education & $1,427(38.91)$ \\
\hline Primary & $1,445(39.39)$ \\
\hline Secondary and above & $796(21.70)$ \\
\hline \multicolumn{2}{|l|}{ Respondent's occupation } \\
\hline Not employed & $1,844(50.27)$ \\
\hline Employed & $1,824(49.73)$ \\
\hline \multicolumn{2}{|l|}{ Husband's occupation } \\
\hline Not employed & $1,844(50.27)$ \\
\hline Employed & $1,824(49.73)$ \\
\hline \multicolumn{2}{|l|}{ Wealth index } \\
\hline Poor & $1,028(28.02)$ \\
\hline Middle & $765(20.85)$ \\
\hline Rich & $1,875(51.14)$ \\
\hline \multicolumn{2}{|l|}{ Media exposure } \\
\hline No & $1,988(54.20)$ \\
\hline Yes & $1,680(45.80)$ \\
\hline \multicolumn{2}{|l|}{ Number of living children } \\
\hline$<=2$ & $1,635(44.56)$ \\
\hline$>2$ & $2,033(55.44)$ \\
\hline \multicolumn{2}{|l|}{ Type of marriage } \\
\hline Monogamy & $3,497(95.3)$ \\
\hline Polygamy & $171(4.7)$ \\
\hline \multicolumn{2}{|l|}{ Couple's age difference } \\
\hline Negative & $119(3.2)$ \\
\hline Equal & $79(2.2)$ \\
\hline$\leq 10$ years & $2,767(75.4)$ \\
\hline$\geq 10$ years & $703(19.2)$ \\
\hline
\end{tabular}

Others $^{+}=$catholic, traditional, and other EDHS categories Others $^{++}=$other EDHS categories. Others ${ }^{+++}=$other EDHS categories.

3.4. Spatial Scan Statistical Analysis. In spatial scan statistics, 1 primary and 4 secondary clusters were identified; the primary cluster is located at $9.306441 \mathrm{~N}, 35.546886 \mathrm{E}$ with a $159.63 \mathrm{~km}$ radius, a Relative Risk (RR) of 1.23, and an LLR of 32.11 (Figure 2 and Table 2). It showed that women inside the spatial window had 1.23 times higher likelihood of being nonautonomous on decision regarding contraceptive utilization than women outside the spatial window. The most likely clusters of nonautonomous women were detected in 


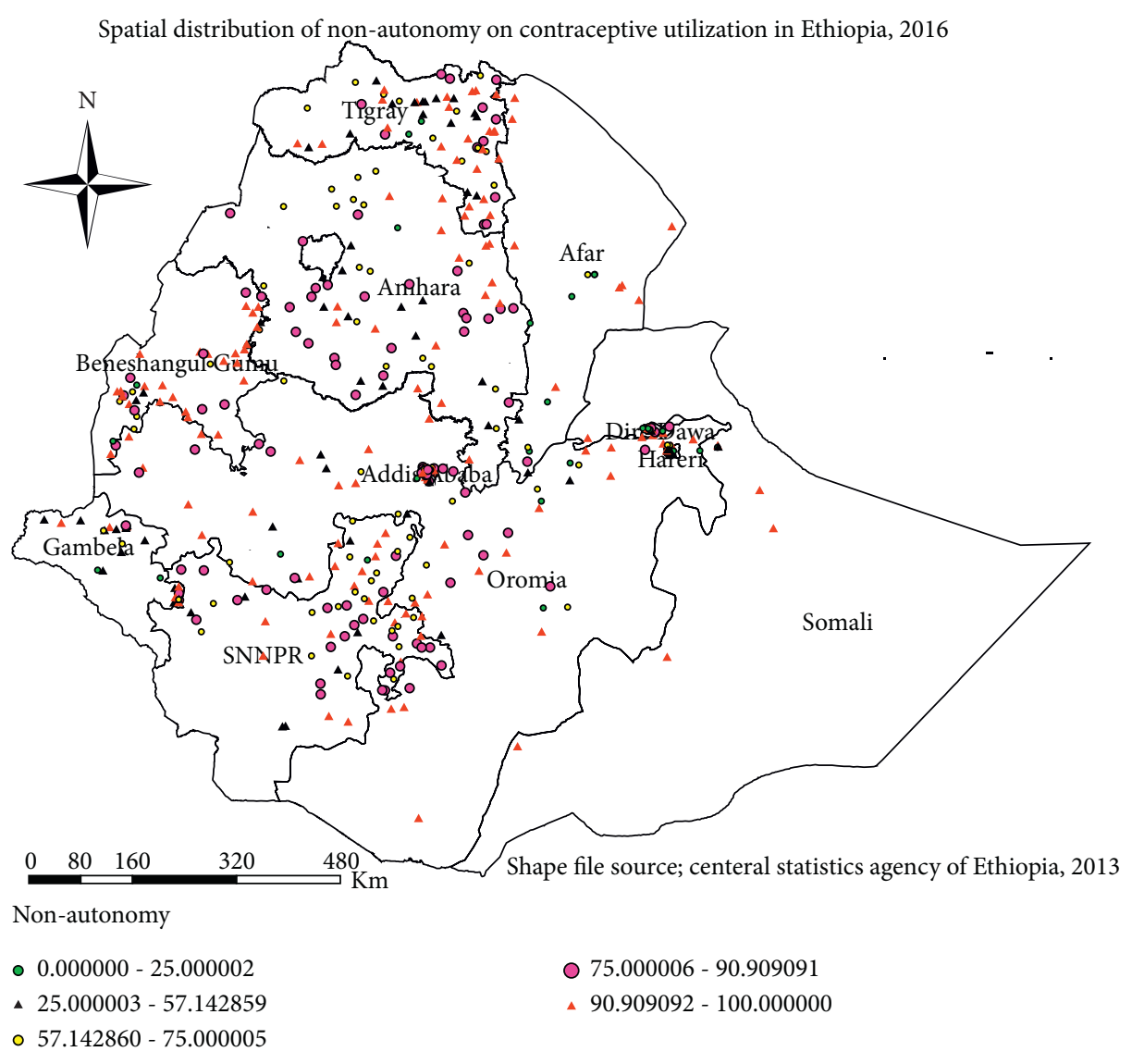

(a)

Figure 1: Continued. 


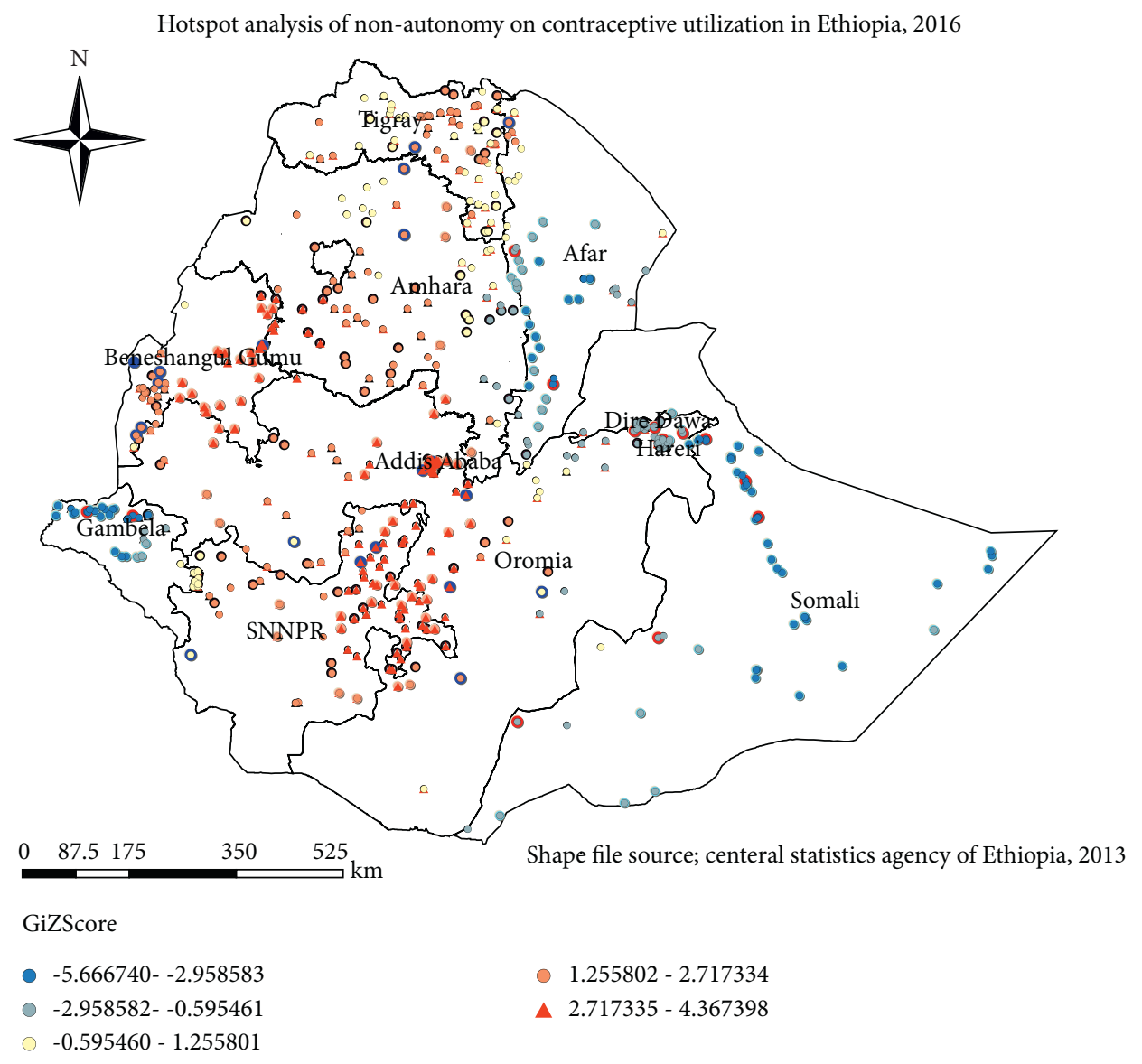

(b)

Figure 1: (a) The spatial distribution of women's nonautonomy on decision regarding contraceptive utilization, Ethiopia, 2016. (b) Hotspot analysis of women's nonautonomy on decision regarding contraceptive utilization, Ethiopia, 2016.

most parts of Benishangul Gumz and western parts of Oromia region.

3.5. Women's Nonautonomy on Decision Regarding Contraceptive Utilization. Overall, 2876 (78.40\% (95\% CI: 77.0\%, $79.7 \%)$ ) women were nonautonomous on contraceptive utilization.

3.6. Result of the Empty (Null) Bayesian Multilevel Logistic Regression Model. The Bayesian null model showed that variance of the random part was 0.46 with a $95 \%$ credible interval of 0.22-0.71, showing EA differences in women's nonautonomy on contraceptive utilization in Ethiopia. The variance estimate, which is greater than zero, indicates that there are EA, differences in nonautonomy on contraceptive utilization among married reproductive-age women in the country.

The unobserved heterogeneity has a logistic distribution with a variance at the individual level equivalent to $\prod^{2} / 3$ (that is, 3.29) [30-32]. Therefore, the ICC $=0.46$ / $0.46+3.29=0.12$, which implied that $12 \%$ of the total variability in nonautonomy on decision regarding contraceptive utilization among married reproductive-age women is due to differences across enumeration areas, and $88 \%$ of the variability is accounted by individual differences. Both the random factor variance and the ICC value were proposed to apply the Bayesian multilevel logistic regression model for additional analysis to handle the heterogeneity between EAs (Table 3).

3.7. Bayesian Multilevel Logistic Regression Analysis. The random-walk Metropolis-Hastings sampling procedure was applied with 12,500 total iterations. After 2,500 burn-in terms were discarded, 10,000 samples were generated from the full posterior distribution. Noninformative normal prior distribution with mean $=0$ and variance $=10^{6}$ for the fixedeffect and gamma distribution with scale $=0.1$ and shape$=0.1$ for the variance of random effect was used. Convergence-assessment plots have confirmed the convergence produced from Markov chains, before taking any inference from the posterior distribution. Before undertaking any inference from the posterior distribution, the convergence generated from Markov chains was proved by convergenceassessment plots (Annex 1)

3.8. Bayesian Multivariable Multilevel Logistic Regression Model. In the Bayesian multivariable multilevel logistic 
Spatial Scan analysis of non-autonomy on contraceptive utilization in Ethiopia, 2016

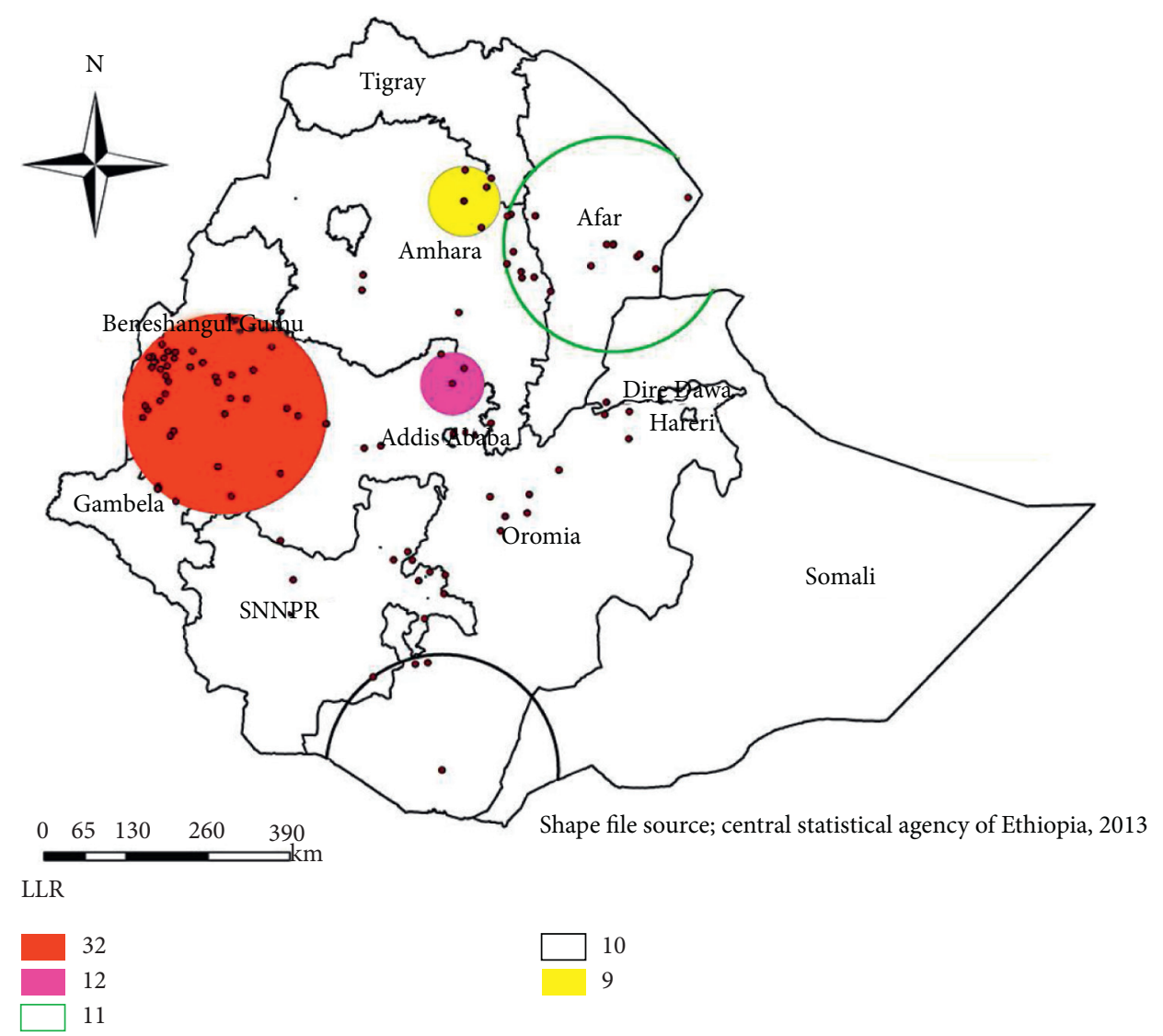

FIgURE 2: Spatial scan statistics of women's nonautonomy on decision regarding contraceptive utilization, Ethiopia, 2016.

TABle 2: The spatial scan statistical analysis of women's decision-making nonautonomy on contraceptive utilization, Ethiopia, 2016.

\begin{tabular}{|c|c|c|c|c|c|c|c|}
\hline Cluster type & Number of significant enumeration areas & Coordinates/radius & Populations & Cases & $\mathrm{RR}$ & LLR & $P$ value \\
\hline 1 & 53 & $(9.306441 \mathrm{~N}, 35.546886 \mathrm{E}) / 159.63 \mathrm{~km}$ & 272 & 259 & 1.23 & 32.11 & $<0.001$ \\
\hline 2 & 3 & $(9.739794 \mathrm{~N}, 38.793594 \mathrm{E}) / 49.89 \mathrm{~km}$ & 65 & 64 & 1.26 & 11.96 & 0.003 \\
\hline 3 & 17 & $\begin{array}{c}(11.731000 \mathrm{~N}, 41.095173 \mathrm{E}) / \\
170.63 \mathrm{~km}\end{array}$ & 100 & 95 & 1.22 & 11.01 & 0.010 \\
\hline 4 & 4 & $(4.211065 \mathrm{~N}, 38.646702 \mathrm{E}) / 183.90 \mathrm{~km}$ & 40 & 40 & 1.28 & 9.72 & 0.021 \\
\hline 5 & 5 & $(12.349051 \mathrm{~N}, 38.961666 \mathrm{E}) / 55.64 \mathrm{~km}$ & 37 & 37 & 1.28 & 8.98 & 0.044 \\
\hline
\end{tabular}

TABLE 3: Estimates for the variance components model of women's decision-making nonautonomy on contraceptive utilization, Ethiopia, 2016.

\begin{tabular}{lcccc}
\hline Fixed effect & Estimate & SDMCSE & 0.013 & $95 \%$ credible interval \\
Intercept & 3.38 & 0.201 & $(3.01,3.79)$ & $95 \%$ credible interval \\
Random effect & Estimate & SD & 0.12 & 0.016 \\
\hline$\delta_{u}^{2}$ & 0.46 & - & & $(0.22,0.71)$ \\
ICC & 0.12 & & - \\
\hline
\end{tabular}

regression model, region, residence, current age, age at first marriage, and wealth index were statistically associated with women's nonautonomy on decision about contraceptive utilization. After adjusting for covariates, the odds of being nonautonomous on contraceptive utilization among women residing in rural settings was $51 \%$ lower than that of those living in an urban area $(\operatorname{AOR}(95 \% \mathrm{CI})=1.34(1.01,1.71))$.

Women who had their first marriage at the age of 18 years and above were $67 \%$ less likely to be nonautonomous on decision to use contraceptives compared to those married 
TABLE 4: Bayesian multilevel multivariable logistic regression of the individual- and community-related variables associated with women's nonautonomy on contraceptive utilization, Ethiopia, 2016.

\begin{tabular}{|c|c|c|c|c|c|c|c|}
\hline \multirow[b]{2}{*}{ Variables } & \multicolumn{7}{|c|}{ Women's autonomy } \\
\hline & No & Yes & $\mathrm{SD}$ & MCSE & $\begin{array}{c}\text { Model II } \\
\text { AOR }(95 \%)\end{array}$ & $\begin{array}{c}\text { Model III } \\
\text { AOR }(95 \%)\end{array}$ & $\begin{array}{c}\text { Model IV } \\
\text { AOR (95\%) }\end{array}$ \\
\hline \multicolumn{8}{|l|}{ Age (years) } \\
\hline 15-24 years & $600(78.7)$ & $162(21.3)$ & - & - & 1 & \multirow{3}{*}{ - } & 1 \\
\hline $25-34$ years & $1040(76.1)$ & $326(23.9)$ & 0.077 & 0.009 & $0.74(0.60,0.90)^{*}$ & & $0.85(0.68,1.03)$ \\
\hline 35-49 years & $614(72.1)$ & $238(27.9)$ & & & $0.48(0.36,0.61)^{*}$ & & $0.63(0.54,0.72)^{*}$ \\
\hline \multicolumn{8}{|l|}{ Religion } \\
\hline Orthodox & $1189(75.0)$ & $397(25.0)$ & & & & \multirow{4}{*}{ - } & 1 \\
\hline Protestant & $512(80.3)$ & $126(19.7)$ & 0.123 & 0.015 & $1.32(1.10,1.57)^{*}$ & & $0.89(0.58,1.37)$ \\
\hline Muslim & $523(72.6)$ & $197(27.4)$ & 0.065 & 0.012 & $0.81(0.69,0.95)^{*}$ & & $0.62(0.42,1.95)$ \\
\hline Others $^{+}$ & $30(83.3)$ & $6(16.7)$ & 0.154 & 0.023 & $1.53(1.25,1.85)^{*}$ & & $0.56(0.18,1.22)$ \\
\hline \multicolumn{8}{|l|}{ Age at $1^{\text {st }}$ marriage } \\
\hline$<18$ years & $1317(76.1)$ & $414(23.9)$ & - & & & & \multirow{2}{*}{$\begin{array}{c}1 \\
0.33(0.19,0.57)^{*}\end{array}$} \\
\hline$\geq 18$ years & $937(75.0)$ & $312(25.0)$ & 0.084 & 0.016 & $0.48(0.22,0.65)^{*}$ & & \\
\hline \multicolumn{8}{|c|}{ Respondent's educational status } \\
\hline No education & $954(75.2)$ & $315(24.8)$ & & & & & \multirow{3}{*}{-} \\
\hline Primary & $792(76.5)$ & $244(23.5)$ & 0.074 & 0.006 & $1.03(0.89,1.18)$ & & \\
\hline Secondary and above & $508(75.3)$ & $167(24.7)$ & 0.09 & 0.015 & $1.09(0.91,1.29)$ & & \\
\hline \multicolumn{8}{|c|}{ Husband's educational status } \\
\hline No education & $683(74.1)$ & $239(25.9)$ & & & & & \multirow{3}{*}{-} \\
\hline Primary & $888(77.8)$ & $253(22.1)$ & 0.732 & 0.012 & $1.05(0.91,1.20)$ & & \\
\hline Secondary and above & $683(74.5)$ & $234(25.5)$ & 0.108 & 0.024 & $0.90(0.72,1.13)$ & & \\
\hline \multicolumn{8}{|l|}{ Husband's occupation } \\
\hline Unemployed & $1121(74.5)$ & $384(25.5)$ & & & & & \multirow{2}{*}{-} \\
\hline Employed & $1133(76.8)$ & $342(23.2)$ & 0.072 & 0.009 & $1.20(1.06,1.36)$ & & \\
\hline \multicolumn{8}{|l|}{ Wealth index } \\
\hline Poor & $532(74.5)$ & $182(25.5)$ & & & & & 1 \\
\hline Middle & $368(78.8)$ & $99(21.2)$ & 0.063 & 0.011 & $0.32(0.09,1.56)$ & & $0.21(0.01,1.10)$ \\
\hline Rich & $1354(75.3)$ & $445(24.7)$ & 0.078 & 0.014 & $0.23(0.05,0.44)^{*}$ & & $0.12(0.03,0.26)^{*}$ \\
\hline \multicolumn{8}{|l|}{ Media exposure } \\
\hline No & $1016(77.1)$ & $301(22.8)$ & & & & & \multirow{2}{*}{-} \\
\hline Yes & $1238(74.4)$ & $425(25.6)$ & 0.099 & 0.014 & $0.89(0.72,1.11)$ & & \\
\hline \multicolumn{8}{|c|}{ Number of living children } \\
\hline$\leq 2$ & $1154(75.2)$ & $380(24.8)$ & & & & & 1 \\
\hline$>2$ & $1100(76.1)$ & $346(23.9)$ & 0.130 & 0.014 & $1.14(1.19,1.72)^{*}$ & & $1.32(0.98,1.62)$ \\
\hline \multicolumn{8}{|l|}{ Residence } \\
\hline Urban & $803(71.2)$ & $325(28.8)$ & & & & 1 & 1 \\
\hline Rural & $1451(78.3)$ & $401(21.6)$ & 0.35 & 0.024 & & $1.61(1.06,2.45)$ & $1.34(1.01,1.71)^{*}$ \\
\hline \multicolumn{8}{|l|}{ Region } \\
\hline Large central & $1357(77.5)$ & $393(22.5)$ & & & & 1 & 1 \\
\hline Small peripheral & $408(79.5)$ & $105(20.5)$ & 0.195 & 0.029 & - & $1.13(0.79,1.56)$ & $1.16(0.92,1.44)$ \\
\hline Metropolitan & $489(68.2)$ & $228(31.8)$ & 0.107 & 0.012 & & $0.62(0.42,0.86)$ & $0.71(0.54,0.91)^{*}$ \\
\hline Community media expo & & & & & & & \\
\hline Low & $1149(77.8)$ & $327(22.2)$ & 0.167 & 0.022 & & 1 & \\
\hline High & $1105(73.5)$ & $399(26.5)$ & & & - & $1.02(0.74,1.42)$ & - \\
\hline Community-level womes & illiteracy & & & & & & \\
\hline Low illiteracy & $1154(77.4)$ & $336(22.6)$ & & & & 1 & \\
\hline High illiteracy & $1100(73.8)$ & $390(26.2)$ & 0.171 & 0.017 & & $1.17(0.85,1.57)$ & \\
\hline Community poverty stat & & & & & & & \\
\hline Low & $1094(74.2)$ & $381(25.8)$ & & & & 1 & \\
\hline High & $1160(77.1)$ & $345(22.9)$ & 0.125 & 0.011 & & $0.76(0.56,1.05)$ & \\
\hline
\end{tabular}

${ }^{*}$ Statistically significant variables at $95 \%$ confidence interval. Others ${ }^{+}=$catholic, traditional, and other EDHS categories.

before 18 years $($ AOR $(95 \%$ CI $)=0.33(0.19,0.57))$. Similarly, women in the age range of $35-49$ years (AOR $(95 \% \mathrm{CI})=$ $0.63(0.54,0.72))$ had lesser odds of being nonautonomous on decision regarding contraceptive utilization compared to younger women.
Our analysis also revealed that the likelihood of being nonautonomous on decision regarding contraceptive utilization was $82 \%$ lower for women in rich households compared to those from poor households (AOR $(95 \% \mathrm{CI})=$ $0.12(0.03,0.26))$. Moreover, women living in metropolitan 
regions were less likely to be nonautonomous on decision regarding contraceptive utilization compared to those in large central regions $(\mathrm{AOR}(95 \% \mathrm{CI})=0.71(0.54,0.91))$ (Table 4).

\section{Discussion}

Women's decision-making autonomy on contraceptive utilization is an essential component of SRH rights [33]. This study assessed the spatial distribution and determinants of nonautonomy on decision regarding contraceptive utilization among married women in Ethiopia. It was revealed that more than three-fourth women in Ethiopia were nonautonomous on decision regarding contraceptive utilization. This finding is higher compared to the results of the studies in different parts of Ethiopia [15-19,34] and South Africa [35]. On the contrary, our finding is lower than in a study in Senegal [36]. The discrepancy might be due to the methodological differences of the studies and variations in the sociocultural and religious context of the study areas.

The spatial analysis showed that, in Ethiopia, the spatial distribution of women's nonautonomy on contraceptive utilization was nonrandom. The clustered pattern was confirmed with hotspot and spatial SaTScan analysis.

Region, residence, wealth index, current age, and age at first marriage were identified as significant factors affecting women's nonautonomy on decision about contraceptive utilization. Accordingly, women from rural areas had increased likelihood of being nonautonomous on contraceptive utilization compared to those residing in urban settings. This finding is consistent with the result of the previous studies in Ethiopia $[20,21]$, which found lower odds of nonautonomy among urban women. This might be because women in urban residences have better educational opportunities and have access to information, particularly on contraceptives and other SRHrelated issues, than their rural counter group, which enables them to have greater involvement in contraceptives and other household decision-making processes.

Women aged 35-49 years were less likely to be nonautonomous on decision regarding contraceptive utilization than women aged 15-24 years. This finding is similar to the previous studies in Ethiopia [19, 21,36]. This might be because younger women are less likely to visit family-planning clinics and lack awareness due to limited access to SRH information [37] and, therefore, have little control over their contraceptive decision. On the contrary, this finding is inconsistent with studies in Southern Ethiopia [16, 18]. Methodological differences might contribute to these variations.

Women who had their first marriage after the age of 18 years and above had decreased odds of being nonautonomous compared to those married before 18 years. This finding is consistent with a previous study [12]. This might be due to the inferior negotiating power of younger women associated with limited educational opportunities as a consequence of early marriage [38, 39].

This study also showed that women who lived in metropolitan regions had decreased likelihood of being nonautonomous on decision regarding contraceptive utilization compared to those in large central regions. Differences in urbanization and access to sexual and reproductive health services and its information which have a direct relation with healthcare decision might have contributed to this finding $[22,40]$.

Furthermore, consistent with the results of previous studies $[12,41]$, this study revealed that women from rich households had lesser odds of being nonautonomous on a decision regarding contraceptive utilization compared to those from poor households. This might be because women in the richer household are more likely to be employed, have an increased level of self-confidence, and have access to information, which could improve their involvement in healthcare decisions [42].

This study has strengths of nationally representative weighted data, and appropriate advanced statistical models were used to account for the clustering effect and to get a reliable standard error and parameter estimates. Moreover, the use of GIS and SaTScan statistical tests helps to detect similar and statistically significant hotspot areas of nonautonomy on decision regarding contraceptive utilization. However, this study has limitations of the cross-sectional nature of the study, which may not indicate true causality.

Public health interventions targeting significant hotspot areas are essential to enhance the autonomy of women on contraceptive utilization. Moreover, the government should promote women's autonomy on contraceptive utilization as an essential component of SRH with particular attention for adolescent women, women living in the poorest households, and those residing in rural settings of the country.

The findings of this study have valuable policy implications for health programme design and interventions. High-risk areas for nonautonomy on contraceptive utilization can be easily identified to make effective local interventions. In general, these findings are of importance for the minister of health, regional health bureaus, and nongovernmental organizations when designing an intervention to reduce nonautonomy on decision on contraceptive utilization in hotspot areas identified by the study.

\section{Conclusions}

More than three-fourths of married reproductive-age women in Ethiopia were nonautonomous on decision regarding contraceptive utilization. A high (hotspot) proportion of women with nonautonomy was found in northern parts of SNNPR, southern parts of Oromia, and Benishangul-Gumuz regions of the country. Region, residence, age, age at first marriage, and wealth index were statistically associated with women's nonautonomy on decision about contraceptive utilization.

\section{Abbreviations}

DIC: Deviance information criterion

AOR: Adjusted odds ratio

DHS: Demographic and Health Survey

EA: $\quad$ Enumeration area 
EDHS: Ethiopian Demographic and Health Survey

ICC: Intraclass correlation coefficient

MCSE: Monte Carlo standard error

MCMC: Markov Chain Monte Carlo

PCV: Proportional change in variance

SD: $\quad$ Standard deviation

SNNPR: Southern Nations, Nationalities, and People's Region

SRH: Sexual and reproductive health.

\section{Data Availability}

Data are available online and can be accessed from https:// www.measuredhs.com.

\section{Conflicts of Interest}

The authors declare that no conflicts of interest.

\section{Authors' Contributions}

SBA, KUM, MSM, and AWT had substantial contributions to the conception and design of this research, involved in the analysis and interpretation of data, and drafted the manuscript. SBA revised and finalized the manuscript. All authors read and approved the final manuscript.

\section{Acknowledgments}

The authors acknowledge the ICF International for granting access to use the 2016 EDHS dataset for this study.

\section{Supplementary Materials}

Annex I: convergence-assessment plots for statistically significant parameters. (Supplementary Materials)

\section{References}

[1] D. R. Acharya, J. S. Bell, P. Simkhada, E. R. Van Teijlingen, and P. R. Regmi, "Women's autonomy in household decisionmaking: a demographic study in Nepal," Reproductive Health, vol. 7, no. 1, pp. 15-22, 2010.

[2] F. F. Fikree, A. Khan, M. M. Kadir, F. Sajan, and M. H. Rahbar, "What influences contraceptive use among young women in urban squatter settlements of Karachi, Pakistan?" International Family Planning Perspectives, vol. 27, no. 3, pp. 130136, 2001.

[3] A. Al Riyami, M. Afifi, and R. M. Mabry, "Women's autonomy, education and employment in Oman and their influence on contraceptive use," Reproductive Health Matters, vol. 12, no. 23, pp. 144-154, 20041.

[4] S. Saleem and M. Bobak, "Women's autonomy, education and contraception use in Pakistan: a national study," Reproductive Health, vol. 2, no. 1, p. 8, 2005.

[5] D. Loll, P. J. Fleming, A. Manu et al., "Reproductive autonomy and modern contraceptive use at last sex among young women in Ghana," International Perspectives on Sexual and Reproductive Health, vol. 45, pp. 1-2, 2019.

[6] O. Alabi, C. O. Odimegwu, N. De-Wet, and J. O. Akinyemi, "Does female autonomy affect contraceptive use among women in northern Nigeria?" African Journal of Reproductive Health, vol. 23, no. 2, pp. 92-100, 2019.

[7] R. Adhikari, D. Acharya, C. L. Ranabhat, and R. Kc, "Factors associated with non-use of contraceptives among married women in Nepal," Journal of Health Promotion, vol. 7, pp. 7-18, 2019.

[8] A. K. Biswas, T. E. Shovo, M. Aich, and S. Mondal, "Women's autonomy and control to exercise reproductive rights: a sociological study from rural Bangladesh," Sage Open, vol. 7, no. 2, Article ID 2158244017709862, 2017.

[9] S. P. Viswan, T. K. S. Ravindran, N. B. Kandala, M. G. Petzold, and S. Fonn, "Sexual autonomy and contraceptive use among women in Nigeria: findings from the demographic and health survey data," International Journal of Women's Health, vol. 9, pp. 581-590, 2017.

[10] D. Y. Atiglo and S. N. A. Codjoe, "Meeting women's demand for contraceptives in Ghana: does autonomy matter?" Women \& Health, vol. 59, no. 4, pp. 347-363, 2019.

[11] S. Yaya, O. A. Uthman, M. Ekholuenetale, and G. Bishwajit, "Women empowerment as an enabling factor of contraceptive use in sub-Saharan Africa: a multilevel analysis of crosssectional surveys of 32 countries," Reproductive Health, vol. 15, no. 1, pp. 214-222, 2018.

[12] UNFPA, “Tracking women's decision-making for sexual and reproductive health and reproductive rights," Sustainable Development Goal Indicator 5.6.1, United Nations Population Fund, New York, NY, USA, 2020, https://www.unfpa.org/ resources/tracking-womens-decision-making-sexual-andreproductive-health-and-reproductive-rights.

[13] T. D. Delbiso, "Gender power relations in reproductive decision-making: the case of Gamo migrants in Addis Ababa, Ethiopia," African Population Studies, vol. 27, no. 2, pp. 118-126, 2013.

[14] A. Eshete and Y. Adissu, "Women's joint decision on contraceptive use in gedeo zone, southern Ethiopia: a community based comparative cross-sectional study," International journal of family medicine, vol. 2017, Article ID 9389072, 9 pages, 2017.

[15] M. Alemayehu, K. Hailesellasie, G. Biruh et al., "Married women's autonomy and associated factors on modern contraceptive use in adwa town, northern Ethiopia," Science Journal of Public Health, vol. 2, no. 4, pp. 297-304, 2014.

[16] D. Dadi, D. Bogale, Z. Minda, and S. Megersa, "Decisionmaking power of married women on family planning use and associated factors in Dinsho Woreda, South East Ethiopia," Open Access Journal of Contraception, vol. 11, pp. 15-23, 2020.

[17] B. Alemayehu, G. M. Kassa, Y. M. Teka, L. B. Zeleke, A. A. Abajobir, and A. A. Alemu, "Married women's decisionmaking power in family planning use and its determinants in basoliben, northwest Ethiopia," Open Access Journal of Contraception, vol. 11, pp. 43-52, 2020.

[18] A. D. Belay, Z. B. Mengesha, M. K. Woldegebriel, and Y. A. Gelaw, "Married women's decision making power on family planning use and associated factors in Mizan-Aman, South Ethiopia: a cross sectional study," BMC Women's Health, vol. 16, no. 1, pp. 1-6, 2016.

[19] M. Alemayehu and M. Meskele, "Health care decision making autonomy of women from rural districts of Southern Ethiopia: a community based cross-sectional study," International Journal of Women's Health, vol. 9, pp. 213-221, 2017.

[20] B. Bogale, M. Wondafrash, T. Tilahun, and E. Girma, "Married women's decision making power on modern contraceptive use in urban and rural southern Ethiopia," $B M C$ Public Health, vol. 11, no. 1, pp. 342-347, 2011. 
[21] Z. K. Edossa, T. F. Debela, and B. A. Mizana, "Women's decision on contraceptive use in Ethiopia: multinomial analysis of evidence from Ethiopian demographic and health survey," Health Services Research and Managerial Epidemiology, vol. 7, Article ID 2333392820924565, 2020.

[22] H. Kloos, "Primary health care in Ethiopia under three political systems: community participation in a war-torn society," Social Science \& Medicine, vol. 46, no. 4-5, pp. 505-522, 1998.

[23] United Nations, Population Division, World Family Planning 2017-Highlights, United Nations, New York, NY, USA, 2017.

[24] G. N. Osuafor, S. M. Maputle, and N. Ayiga, "Factors related to married or cohabiting women's decision to use modern contraceptive methods in Mahikeng, South Africa," African Journal of Primary Health Care and Family Medicine, vol. 10, no. 1, pp. 1-7, 2018.

[25] UNFPA, Sexual and Reproductive Health for All: Reducing Poverty, Advancing Development and Protecting Human Rights, United Nations Population Fund, New York, NY, USA, 2010.

[26] Federal Democratic Republic of Ethiopia Ministry of Health, "National reproductive health strategy 2006-2015," 2006, https://www.exemplars.health/-/media/resources/underfivemortality/ethiopia/ethiopia-fmoh_national-reproductive-healthstrategy.pdf?la=e $n$.

[27] Federal Democratic Republic of Ethiopia, "Constitution of the federal democratic republic of Ethiopia," 1995, https://www. refworld.org/docid/3ae6b5a84.html.

[28] The Federal Democratic Republic of Ethiopia Ministry of Health, "Health Sector transformational plan-HSTP 2015/16-2019/20 (2008-2012 EFY)," 2015, https://www. globalfinancingfacility.org/ethiopia-health-sector-transformationplan-201516-201920.

[29] Central Statistical Agency (CSA) [Ethiopia] and ICF, Ethiopia Demographic and Health Survey 2016, CSA and ICF, Rockville, MA, USA, 2016.

[30] H. Goldstein, W. Browne, and J. Rasbash, "Partitioning variation in multilevel models," Understanding Statistics, vol. 1, no. 4, pp. 223-231, 2002.

[31] R. Jon, S. Fiona, J. William, Browne, and G. Harvey, "Logistic models for binary and binomial responses," A User's Guide to MLwiN, University of Bristol, Bristol, UK, 2003.

[32] T. A. Snijders and R. J. Bosker, Multilevel Analysis: An Introduction to Basic and Advanced Multilevel Modeling, Sage, Thousand Oaks, CA, USA, 2011.

[33] UNFPA, "Sexual and reproductive health and rights: the cornerstone of sustainable development," 2018, https://www. un.org/en/chronicle/article/sexual-and-reproductive-healthand-rights-cornerstone-sustainable-development.

[34] S. Yonas Tadesse, A. Aragaw Emiru, T. Ejigu Tafere, and M. Belachew Asresie, "Women's autonomy decision making power on postpartum modern contraceptive use and associated factors in north west Ethiopia," Advances in Public Health, vol. 2019, Article ID 1861570, 7 pages, 2019.

[35] National Department of Health and ICF, South Africa Demographic and Health Survey 2016, National Department of Health-NDoH-ICF, Pretoria, South Africa, 2019.

[36] N. M. Sougou, O. Bassoum, A. Faye, and M. M. Leye, "Women's autonomy in health decision-making and its effect on access to family planning services in Senegal in 2017: a propensity score analysis," BMC Public Health, vol. 20, pp. 1-9, 2020.

[37] D. Rios-Zertuche, L. C. Blanco, P. Zúñiga-Brenes et al., "Contraceptive knowledge and use among women living in the poorest areas of five Mesoamerican countries," Contraception, vol. 95, no. 6, pp. 549-557, 2017.
[38] S. A. Mim, "Effects of child marriage on girls' education and empowerment," Journal of Education and Learning, vol. 11, no. 1, Article ID 9, 2017.

[39] Guilbert N. Early marriage, women empowerment and child mortality: married too young to be a «good mother»?

[40] G. A. Tesema, Y. Yeshaw, A. Kasie, A. M. Liyew, A. B. Teshale, and A. Z. Alem, "Spatial clusters distribution and modelling of health care autonomy among reproductive-age women in Ethiopia: spatial and mixed-effect logistic regression analysis," BMC Health Services Research, vol. 21, no. 1, pp. 1-2, 2021.

[41] UNFPA, "Research on factors that determine women's ability to make decisions about sexual and reproductive health and rights," 2019, https://www.unfpa.org/resources/researchfactors-determine-womens-ability-make-decisions-aboutsexual-and-reproductive.

[42] P. E. Osamor and C. Grady, “Women's autonomy in health care decision-making in developing countries: a synthesis of the literature," International Journal of Women's Health, vol. 8, Article ID 191, 2016. 